\title{
Global science and global
}

\section{peace}

\author{
Ahmed Zewail, \\ California Institute of Technology, Pasadena, California, U.S.A.
}

$T^{\mathrm{n}}$ the past five years, the scientific community worldwide has published about 3.5 million research papers. Europe's share is 37 percent. The U.S. share is 34 percent. The Asia/Pacific share is 22 percent. Other parts of the globe-representing 70 to 80 percent of the world's population living largely in developing countrieshave contributed less than 7 percent of these scientific articles.

What difference does this disparity in academic output make? Should only universities and research centers be concerned? Perhaps not. Consider this interesting correlation. The U.S. contribution to the world's annual economic output is between 30 and 40 percent, comparable to its share of scientific output on a global scale. Europe's annual economic output registers a similar percentage and, like the U.S., its economic output tracks its output of scientific contributions. And where there is prosperity and scientific achievement, there is often democracy. It is unlikely that these correlations are coincidental.

If we are aware of these trends and understand the problems that stand in the way of progress, why does the developing world continue to have such difficulties building scientific capacity and putting science to work to improve its economic well-being? And, what can the "haves" and "have-nots" do to change the current situation that threatens global peace and progress?

A renaissance in thinking is needed. The developing and developed worlds each shoulder responsibilities in efforts to build societies that are enlightened by science education and benefit from the revolutionary economical developments of science and technology. As someone who has citizenship in both worlds, with roots in an ancient civilization that was highly "developed", but is now considered "developing", and who currently lives and practices in a developed nation, I perhaps can speak to these questions from both perspectives.

For the developing world, the first and foremost priority should be for it to get its own house in order. It should not simply wait for the developed world to help, or accuse people there of engaging in conspiracy theories. Yes, international politics play a significant role, but people's will is a stronger force, provided the force is coherent and not dispersed by internal politics.

Specifically, the developing world must create new systems of education that eradicate illiteracy and emphasize rational thinking. The objective is to build a new workforce equipped with 21 st century tools of education and skills and with a belief in ethics and teamwork. Women must be included in the educational process not only because they deserve to be given an opportunity to succeed, but because societies cannot progress without them. Clearly, this may not be possible on a grand scale in a short time, but the foundation must be established properly and in a timely manner.

Developing countries, moreover, should implement a meritbased system that rewards excellence. Science in much of the developing world relies too much on seniority and puts decisionmaking into too few hands. The result is a snail-paced environment in a fastpaced world. The developing world is No country can rich in human and material resources. But to take advantage of these invalu-
able resources, strategies have to be develop centers able resources, strategies have to be of excellence achievements of scientists and scholars so that the best among them are encouraged to stay at home and pursue unless it creates work that their countries so desperately need.

the right milieu 'Such long-standing problems have to be addressed in an honest and clear for researchers. way. Leadership should be the reward for competence; centers of excellence for science and technology should be for fostering creativity. No country can develop centers of excellence unless it creates the right milieu for researchers. That means identifying and investing in talent and putting in place a merit-based system that minimizes bureaucracy and maximizes freedom and flexibility. The benefits to the country and the world are enormous. Besides the obvious benefits of science and technology, the power of knowledge enhances national pride, limits the brain drain, and leads the country into economic prosperity and effective participation in globalization.

Cheap labour may have worked for developing countries in the past but it will not work in the 21 st century. How can the developing world embrace such economy-transforming technologies as microcomputing, genetic engineering, and information technologies without a strong foundation in science and education? Does the developing world always have to wait decades or centuries before participating in global science and technology? Cannot the new society be a part of the modern world without losing cultural and religious identities? Despite all the political and economic problems, progress is still possible. But change from within is the first ingredient.

For the developed world, the concerns are of similar magnitude but of a different nature. The developed world carries important responsibilities in its efforts to promote the scientific capacity and technological advancement in the developing world. First and foremost it must reform its international aid programs, investing less money on military hardware and instruction and more on scientific education, technology training, and partnerships. The amount of money spent on a few fighter planes could fund many of these programs throughout the developing world, helping in what must be our ultimate goal-global education, peace, and prosperity.

International aid programs, moreover, should be drained of politics to ensure money is available for productive initiatives between developed and developing countries, helping to boost 
science and technology in the developing world. As important, we need visionary leaders who understand the problems of the havenots and are deeply committed to political and economic fairness.

What will wealthy countries receive in return for the help they give to the have-nots? The first reward lies in the moral dimension. The psychological value derived from being a generous global neighbor should not be underestimated. Even on a personal level, most of us do try to help one another and all major religions encourage and legitimize helping the needy. It is also difficult to ignore that the prosperity of the developed world is in part due to natural and human resources from the developing world and its markets.

The second reason for helping is to maintain bridges of continuity between civilizations. By looking back in time and by thinking about the future, one can see that reciprocity between civilizations has been a natural and necessary component for scientific advancement. Islamic civilization gave a great deal to Europe, especially during the Dark Ages. The Arab and Islamic civilizations, which at one time were the world's foremost economic

and scientific powers, were major contributors to the European Renaissance. Today it is the Muslim world that is in need of help and it is appropriate that the United States, Europe, Japan, and other developed nations should in turn lend a hand as a modest gesture to the changing fortunes of history.

Finally, there is a more practical, self-centered consideration based on the time-tested importance of having an adequate insurance policy. In the United States, we pay a great deal for insurance to protect our families against the high cost of medical care, to protect our houses against fire and theft, and to protect our cars against accidents. Similarly, the developed world needs to invest in an insurance policy to help it live in a safer and more secure world.

The choice for the haves is clear-to help in a genuine and sincere manner. Neither hegemony nor shields and missiles will provide adequate security in a world with 4.8 billion people classified as developing or underdeveloped. The choice for the have-nots is also clear-to first get their house in order and build the confidence for a transition to a developed-world status. The developed and developing worlds can achieve their objectives by participating as partners in a dialogue for the sake of global peace and stability. Such a dialogue among civilizations and cultures should not be confused with slogans theorizing about conflicts between religions or cultures.

At its core, we should nurture a dialogue between the haves and have-nots. What is needed is visionary leadership, economic progress, and perspectives that rely on rational thinking. And if we truly believe in fostering democracies around the globe, science is the best vehicle for engendering that democracy. Global science unites citizens of the world through one common language and empowers them with the critical thinking needed to overcome dogmas and misconceptions. Only with knowledge and rationality can we hope for a genuine global peace.

\section{The status of physics}

\section{teaching and research in}

\section{Palestine}

\author{
Y.I. Salamin and N.M. Jisrawi, \\ Dept. of Physics, Birzeit University, West Bank, Palestine
}

$M$ ore than ten years ago, one of us (YIS) listened, at the International Center for Theoretical Physics in Trieste, Italy, to a distinguished African mathematician lecture about "the future of mathematics in Africa". The lecturer started by saying, in almost as many words, that he could describe the future of mathematics in Africa by a single word: "bleak", and that we, his audience, could go home immediately. Unfortunately, the same thing can be said today about physics in Palestine. Strangely enough, physics in Palestine suffers from pretty much the same symptoms that are prevalent in other developing countries when you expected it to be uniquely bad. Let us illustrate:

Money, or rather lack of it, is issue number one! The problems start at the school level. Schoolteachers are not well paid, their schools can not afford to have adequately equipped labs, and they teach outdated curricula to often very large classes. As a consequence, a high-school physics-teaching job is not what most bright young men and women would like to consider training for. All bright young kids (their parents acquiescing) would like to become doctors, engineers, or lawyers, to the detriment of those professions in a shambled economy that seems to barely sustain a corrupt clan of politicians who, mostly without college degrees and hence ignorant of the role of education in development, have naturally opted for preserving the status quo in schools, colleges and universities.

Palestinian colleges and universities, (there are eight of them in the West Bank and two in Gaza with a total student population of a little more than 70,000 ) grew during, or should we say in spite of, the Israeli occupation. With conditions here slightly better for teaching, physicists aspire to realize their potential in another demanding sphere: research. Unfortunately, lack of the necessary infrastructure and funding to do research puts to rest the research careers of most scientists in a developing nation, rather prematurely. At our institution, for example, we can confidently assert that no money is set aside to doing research in physics in the overall annual budget. Worse yet, the institution stopped paying for journal subscriptions a long time ago (e.g., we stopped getting the Physical Reviews in 1992). We don't have any hope of getting publication charges paid by the institution (one of us was advised at a certain point in time by a highly-ranking official to avoid publishing in journals that require such charges, and recommended a few, rather obscure, alternatives!). Talk about building research laboratories with institutional funds is a luxury.

At institutions like ours, a semi-paradox prevails. Faculty members are required to produce, admittedly little, publishable research work in order to be promoted to the higher professorial ranks. To help them in the process, the institutions contribute next to nothing. If they are to do any meaningful research, they often do it on top of heavy teaching responsibilities. For example, requests of a twentyfive percent release from teaching, by one of us, have all been turned down at the beginning of every one of the past few years. 